\title{
Merkel Cell Polyomavirus Infection in a Patient With Merkel Cell Carcinoma: A Case Report
}

\author{
Farzin Sadeghi ; Alireza Ghanadan ${ }^{2}$; Mostafa Salehi Vaziri ${ }^{1}$; Farah Bokharaei Salim ${ }^{3}$; Seyed \\ Hamidreza Monavari ${ }^{3}$; Hossein Keyvani ${ }^{3,{ }^{*}}$ \\ ${ }_{1}^{1}$ Department of Virology, School of Public Health, Tehran University of Medical Sciences, Tehran, IR Iran \\ ${ }^{2}$ Department of Dermatopathology, Razi Skin Hospital, Faculty of Medicine, Tehran University of Medical Sciences, Tehran, IR Iran \\ ${ }^{3}$ Department of Virology, School of Medicine, Iran University of Medical Sciences, Tehran, IR Iran \\ ${ }^{*}$ Corresponding author: Hossein Keyvani, Department of Virology, School of Medicine, Iran University of Medical Sciences, Tehran, IR Iran. Tel: +98-2188602205, Fax: +98-2188602205, \\ E-mail: sadeghifarzin6@gmail.com
}

Received: January 26, 2014; Revised: April 11, 2014; Accepted: April 15, 2014

\begin{abstract}
Introduction: Merkel cell carcinoma (MCC) is a rare and highly aggressive malignancy of the skin which occurs mainly in old people and is very uncommon in young individuals. A new tumor virus belonging to the Polyomaviridae family; Merkel Cell Polyomavirus (MCPyV) has recently been identified in more than $80 \%$ of MCCs.

Case Presentation: We conducted a retrospective review on the archives of the Department of Pathology; Imam Khomeini Hospital Cancer Institute affiliated to Tehran University of Medical Sciences to confirm the MCC samples and we found medical records and samples of a young case with MCC who developed leg skin and scalp tumor six and seven years after bone marrow transplantation, respectively. We analyzed patient formalin-fixed paraffin-embedded samples for the presence of MCPyVDNA using polymerase chain reaction (PCR) method, and the PCR amplicons were subjected to DNA sequencing. Merkel Cell Polyomavirus DNA was detected in both tumors from patient and sequence analysis of the viral LT3 region showed a close homology to strains circulating worldwide.

Conclusions: The findings of this study are consistent with the hypothesis that local, systemic, or tumor-induced immunosuppression may allow the $M C P y V$ to initiate skin aggressive cancer. It is necessary to maintain regular check over patients taking immunosuppressive medications for MCPyV infection. Since there is not any information about detection and molecular biology analysis of MCPyV among Iranian patients with MCC, this study provides more information about MCC and MCPyV in Iran.
\end{abstract}

Keywords:Merkel cell carcinoma; Merkel Cell Polyomavirus; Polyomaviridae

\section{Introduction}

Merkel cell carcinoma (MCC) is a rare and often malignant neuroendocrine cancer of the skin that usually reported in the elderly white people and only five percent of cases are younger than 50 years old at the time of diagnosis (1). Significant clinical characteristics of MCC have been summarized in an acronym: AEIOU (asymptomatic) lack of tenderness, expanding rapidly, immune suppression, older than 50 years, ultraviolet exposed/fair skin)(2). Recently, a new human tumor virus belonging to the Polyomaviridae family and as a cause of MCCs is discovered, this virus is known as Merkel Cell Polyomavirus (MCPyV) (3). Merkel Cell Polyomavirus is a widespread, harmless member of the human viral flora which can launch cancer if it acquires a set of mutations in a susceptible host (elderly, patients with hematological malignancies or immunosuppression).

Infection with MCPyV usually occurs early in childhood and is asymptomatic, after which virus localizes in the body. Under very specific conditions like loss of immune surveillance, virus genome may clonally integrated into the host's genome. The integrated viral genome frequent- ly contains specific truncating mutations in viral tumor antigen ( $\mathrm{T}$ antigen) that prevent virus replication within the cells and disturb cellular signaling pathways. When this occurs tumor formation takes place $(2,4)$. There are a large number of studies about MCPyV detection in patients with MCC from United States, Europe, Australia, and South East Asia but little is known about the other regions, especially Middle East (5-10). We herein carried out a retrospective review from archives of the Department of Pathology, Imam Khomeini Hospital Cancer Institute to confirm MCC samples, and then we found medical records and samples of a young case with MCC. We performed a molecular biologic analysis on the case formalin-fixed paraffin-embedded samples and detected $M C P y V$ sequences for the first time in an Iranian MCC patient.

\section{Case Presentation}

According to Imam Khomeini Hospital medical records a 25-year-old man was admitted to the Imam Khomeini Hospital Cancer Institute in December 2008 for a rap-

Copyright (C) 2015, Ahvaz Jundishapur University of Medical Sciences. This is an open-access article distributed under the terms of the Creative Commons Attribution-NonCommercial 4.0 International License (http://creativecommons.org/licenses/by-nc/4.0/) which permits copy and redistribute the material just in noncommercial usages, provided the original work is properly cited. 
idly growing mass on his left leg that had appeared two months earlier. The patient underwent bone marrow transplantation due to Hodgkin's lymphoma in 2002. Upon physical examination a $5 \times 3 \mathrm{~cm}$, solitary, firm, shiny red-purple nodule was noted (unfortunately there was not any photo from lesion in his medical records). Examination of the inguinal region revealed superficial lymph nodes enlargement. The patient subjected to surgical mass excision and histopathological examination by routine hematoxylin-eosin staining mainly showed subcutaneous tissue which is focally infiltrated by neoplastic cells composed of small round cells with scant eosinophilic cytoplasm, round hyperchromatic nuclei arranged individually and finely dispersed salt and pepper nuclear chromatin (Figure 1 A).

The immunohistochemical staining of the tumor cells showed the characteristic perinuclear dot-like patterns of cytokeratin 20 (CK20) and was negative for cytokeratin-7 (CK7), leukocyte common antigen (LCA) and thyroid transcription factor 1 (TTF1) (Figure $1 \mathrm{~B}$, negative results not shown). On the basis of immunohistochemical features, MCC diagnosis was established. In July 2009, eight months after the surgical removal of the leg skin tumor, patient complained of a solitary, $5 \times 4 \mathrm{~cm}$ nodule on his scalp. The mass was removed by surgical operation and MCC was found in the resected specimen by either hematoxylin-eosin stain or immunostaining for CK20. The patient passes away eight month later. The Formalin-fixed paraffin-embedded tissue sections were investigated to determine if they harbored MCPyVDNA sequences or not. Tissue sections (10 $\mu \mathrm{m}$ thick) were deparaffinized with xylene and subjected to absolute ethanol to remove the xylene. Genomic DNA was then extracted using a QIAamp DNA Mini kit (Qiagen GmbH, Hilden, Germany) according to the manufacturer's instructions.

A 123-base pair (bp) segment of human $\beta$-globin gene was used as amplification control to ascertain the quality of the DNA, as described previously (11). For detection of $M C P y V$ DNA, LT3 primer which is very specific for amplification of the MCPYV T antigen (TAg) sequence was used (3). All primers were synthesized by Metabion International AG (Martinsried, Germany). Merkel Cell Polyomavirus DNA was detected in both tumors of patient (Figure 2 A) and 309 bp putative PCR product was cloned into the pTZ57R/T PCR cloning vector (InsTAclone ${ }^{\mathrm{TM}}$ PCR cloning Kit, Fermentas, MD, USA), then submitted for sequencing (Bioneer, Daejeon, South Korea). The sequences were aligned with reference sequences of MCPyV (MCC350, MCC339, TKS, MKL-1) using the National Center for Biotechnology Information Blast algorithm. The sequences were deposited in GenBank with the Accession Numbers KF442250 and KF442251. The results of sequence alignment showed that they were $100 \%$ identical to those of the MCC339 and MKL-1 isolates.

\section{Discussion}

In 2008, DNA genome of a new tumor virus, $M C P y V$, discovered clonally integrated into the genomes of MCC patients, indicating infection prior to clonal expansion of the tumor cells (3). Association between MCPyV and MCC has been supported by the other studies and it is the only member of the Polyomaviridae family convincingly linked to human cancer (5-8). Merkel Cell Polyomavirus turned out to be a ubiquitous virus among human populations and its seroprevalence ranges between $45-81 \%$ (12-14). Low amounts of viral DNA have been detected in the large spectrum of normal human tissues and in healthy skin flora (4). Under suitable conditions like ultraviolet light (UV) exposure, host immunosuppression and hematological malignancies, this harmless virus can acquires signature mutations in the large T antigen (LTAg) coding portion of its genome, fortuitously integrates into the host genome and initiate tumorigenesis $(15,16)$.

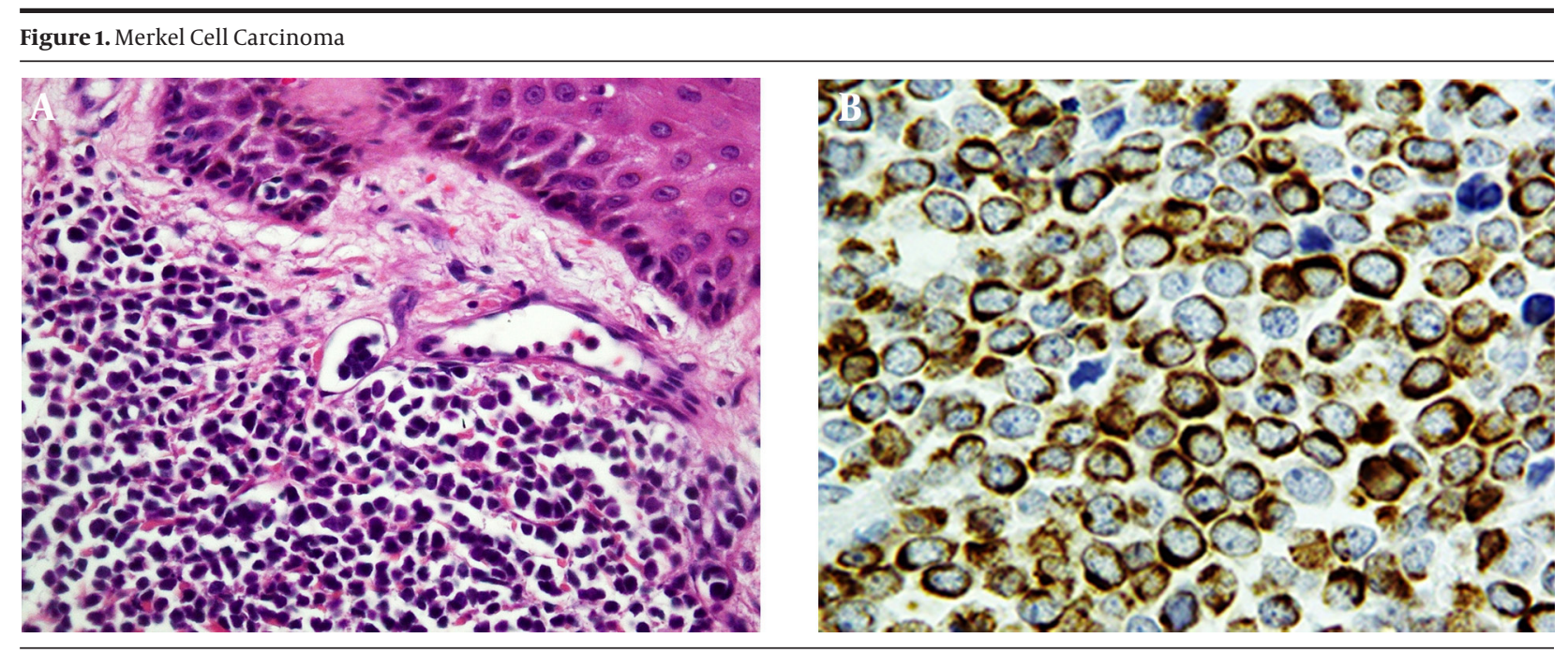

A, Small round cells with hyperchromatic nuclei and scant cytoplasm in dermis with invasion into lymphatic vessels (H\&E staining, original magnification $\times 20)$; B, Immunoreaction with CK20 shows perinuclear dots (CK20, original magnification $\times 40$ ). 
Figure 2. Merkel Cell Polyomavirus DNA Detection in an Iranian Patient With Merkel Cell Carcinoma

A

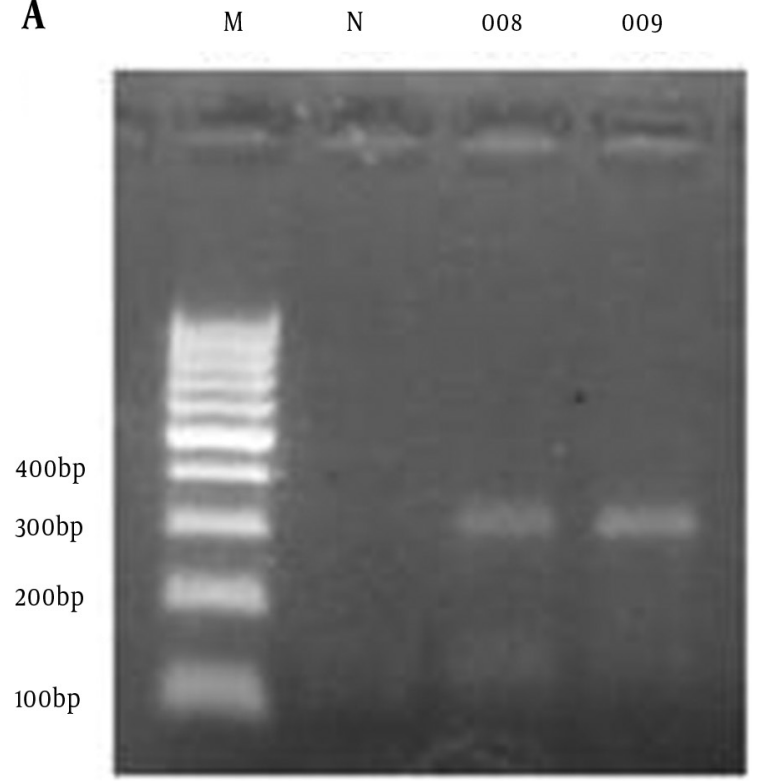

B

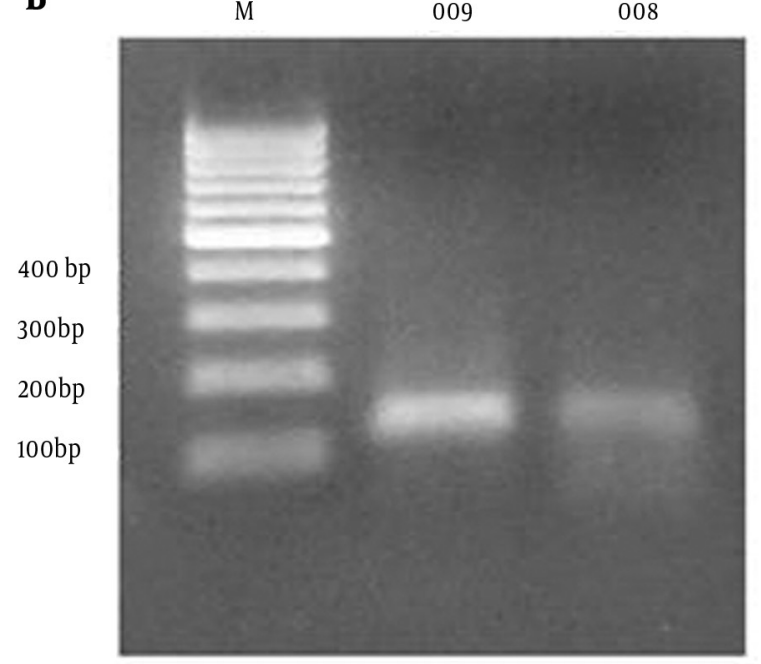

The PCR products amplified with the LT3 primers and analyzed on 2.0\% agarose gel electrophoresis. A, Lane M:100-bp DNA marker; Lane N: Negative control, Lane 008: PCR product (309 bp) of patient leg skin tumor in 2008, Lane 009: PCR product (309bp) of patient scalp tumor in 2009. B, Result of beta-globin housekeeping gene PCR assay to monitor DNA extraction efficiency, Lane M:100-bp DNA size marker; Lane 009: PCR product (123 bp) of patient scalp tumor in 2009, Lane 008: PCR product (123 bp) of patient leg skin tumor in 2008.

Patients undergoing bone marrow transplantation are much more liable to develop malignancy. Immunosuppressive therapy, body irradiation and treatment for graft-versus-host disease (GVHD) may act on the ability of the immune surveillance system against cancerous cells and invading pathogens like human tumor viruses. MCC arises much more often among organ transplant and patients with AIDS (2). In the present study, we report the first case of $M C P y V$ infection in an Iranian patient with MCC and to our knowledge, no previous reports have been published before in our country. This was the first $M C P y V$ isolate from Iran and according to the nucleotide sequence of LT3 fragment it is very similar to the viruses originated from United States and Europe. We presented here a case of MCC in a young patient underwent bone marrow transplantation, which is a very rare case.

Microscopically tumor sections showed a histopathologic and immunohistochemical staining pattern compatible with MCC consists of small basophilic cells with scant cytoplasm and oval, medium-size nuclei. Immunohistochemically perinuclear CK20 positivity and TTF-1 negativity distinguish MCCs efficiently from other small cell carcinomas (17). It is notable to indicate there was a slight possibility that the tumor may cause a new primary infection in the scalp rather than a metastasis from the earlier leg skin tumor. This possibility ruled out by $100 \%$ sequence identity in LT3 fragment between leg skin and scalp tumor viruses. In conclusion our report presents $M C P y V$ detection in a young patient underwent bone marrow transplantation with MCC in Iran for the first time and further studies are required to establish the prevalence of MCPyV in Iranian MCC patients.

\section{Acknowledgements}

The authors thankfully acknowledge the support of the Dr. Issa Jahanzad, Head of Pathology Department; Imam Khomeini Hospital Cancer Institute, for his collaboration. We are also grateful to Sedigheh.Taghinezhad Saroukalaei for her help in cloning.

\section{Authors' Contributions}

Farzin Sadeghi, Alireza Ghanadan and Mostafa SalehiVaziri; developed the study concept, experimental protocols and prepared the manuscript. Hossein Keyvani, Farah Bokharaei-Salim and Seyed Hamidreza Monavari; carried out administrative, technical, and material supports.

\section{Funding/Support}

This study was financially supported by a grant from Tehran University of Medical Sciences (Project code: 9201-30-20990).

\section{References}

1. Goessling W, McKee PH, Mayer RJ. Merkel cell carcinoma. J Clin Oncol. 2002;20(2):588-98.

2. Heath M, Jaimes N, Lemos B, Mostaghimi A, Wang LC, Penas PF, et al. Clinical characteristics of Merkel cell carcinoma at diagnosis in 195 patients: the AEIOU features. J Am Acad Dermatol. 2008;58(3):375-81.

3. Feng $\mathrm{H}$, Shuda M, Chang Y, Moore PS. Clonal integration of a polyomavirus in human Merkel cell carcinoma. Science. 2008;319(5866):1096-100. 
4. Foulongne V, Sauvage V, Hebert C, Dereure O, Cheval J, Gouilh MA, et al. Human skin microbiota: high diversity of DNA viruses identified on the human skin by high throughput sequencing. PLoS One. 2012;7(6)

5. Kassem A, Technau K, Kurz AK, Pantulu D, Loning M, Kayser G, et al. Merkel cell polyomavirus sequences are frequently detected in nonmelanoma skin cancer of immunosuppressed patients. Int J Cancer. 2009;125(2):356-61.

6. Andres C, Belloni B, Puchta U, Sander CA, Flaig MJ. Prevalence of MCPyV in Merkel cell carcinoma and non-MCC tumors. J Cutan Pathol.2010;37(1):28-34.

7. Garneski KM, Warcola AH, Feng Q, Kiviat NB, Leonard JH, Nghiem P. Merkel cell polyomavirus is more frequently present in North American than Australian Merkel cell carcinoma tumors. J Invest Dermatol. 2009;129(1):246-8.

8. Dworkin AM, Tseng SY, Allain DC, Iwenofu OH, Peters SB, Toland AE. Merkel cell polyomavirus in cutaneous squamous cell carcinoma of immunocompetent individuals. I Invest Dermatol. 2009;129(12):2868-74.

9. Katano H, Ito H, Suzuki Y, Nakamura T, Sato Y, Tsuji T, et al. Detection of Merkel cell polyomavirus in Merkel cell carcinoma and Kaposi's sarcoma. J Med Virol. 2009;81(11):1951-8.

10. Nakajima H, Takaishi M, Yamamoto M, Kamijima R, Kodama H, Tarutani M, et al. Screening of the specific polyoma virus as diagnostic and prognostic tools for Merkel cell carcinoma.J Dermatol

\section{Sci. 2009;56(3):211-3.}

11. Saiki RK, Gelfand DH, Stoffel S, Scharf SJ, Higuchi R, Horn GT, et al Primer-directed enzymatic amplification of DNA with a thermostable DNA polymerase. Science. 1988;239(4839):487-91.

12. Chen T, Hedman L, Mattila PS, Jartti T, Ruuskanen O, SoderlundVenermo M, et al. Serological evidence of Merkel cell polyomavirus primary infections in childhood. J Clin Virol. 2011;50(2):125-9.

13. Tolstov YL, Pastrana DV, Feng H, Becker JC, Jenkins FJ, Moschos S, et al. Human Merkel cell polyomavirus infection II. MCV is a common human infection that can be detected by conformational capsid epitope immunoassays. Int J Cancer. 2009;125(6):1250-6.

14. Viscidi RP, Rollison DE, Sondak VK, Silver B, Messina JL, Giuliano AR, et al. Age-specific seroprevalence of Merkel cell polyomavirus, BK virus, and JC virus. Clin Vaccine Immunol. 2011; 18(10):1737-43.

15. Shuda M, Feng H, Kwun HJ, Rosen ST, Gjoerup O, Moore PS, et al. $\mathrm{T}$ antigen mutations are a human tumor-specific signature for Merkel cell polyomavirus. Proc Natl Acad Sci U S A. 2008;105(42):16272-7.

16. Martel-Jantin C, Filippone C, Cassar O, Peter M, Tomasic G, Vielh P, et al. Genetic variability and integration of Merkel cell polyomavirus in Merkel cell carcinoma. Virology. 2012;426(2):134-42.

17. Jaeger T, Ring J, Andres C. Histological, immunohistological, and clinical features of merkel cell carcinoma in correlation to merkel cell polyomavirus status. J Skin Cancer. 2012;2012:983421. 